\title{
Some Aviation Equipment Fault Diagnosis Application Analysis of One Advanced FCM Cluster Algorithm
}

\author{
Libin Yang ${ }^{1}$, Guangyi Zhang ${ }^{2}$ and Yanqin Su, ${ }^{3, *}$ \\ ${ }^{1}$ Department of Ordnance Science and Technology, Naval Aeronautical and Astronautical University, Yantai, Shandong, China \\ ${ }^{2}$ Department of Science Research, Naval Aeronautical and Astronautical University, Yantai, Shandong, China \\ ${ }^{3}$ Department of Control Engineering, Naval Aeronautical and Astronautical University, Yantai, Shandong, China \\ ${ }^{*}$ Corresponding author
}

\begin{abstract}
There is the vague boundary between fault omen and fault phenomenon of aviation equipment, one Fuzzy C-means (FCM) cluster method is given to divide the fault classification, which provide some help to determine the next fault mode.
\end{abstract}

Keywords-FCM; equipment; fault diagnosis

\section{INTRODUCTION}

Because the equipment working status variation, the boundary between the fault mode is not clear, and some fault character description is not certain, the relationship between the fault and character exist some fuzzy nature [1]. In this time, Fuzzy Set Theory fault diagnosis method is suited, and there are often two methods, their difference is whether the data sample omen and fault relationship is known [2]. Now there are many fuzzy cluster methods[3], including the cluster based on the fuzzy equal relationship, the cluster based on the fuzzy similar relationship and Fuzzy C-means (FCM) cluster. FCM is proposed by Dunn and Bezdek to divide according to the minimum mean variance.

\section{THE BASIC CONCEPTION OF FUZZY SET}

Fuzzy Cluster diagnosis finds the similar between the current fault omen sample and the history record. FCM is the fuzzy cluster method based on the target function, and the cluster problem is considered as the restraint unlined plan problem, and gets the fuzzy cluster results through sample set.

Suppose there are $\mathrm{n}$ sample in the equipment original fault data $U$ need to be divided, and m character index, and the data matrix is established as

$$
U=\left[\begin{array}{cccc}
u_{11} & u_{12} & \cdots & u_{1 m} \\
u_{21} & u_{22} & \cdots & u_{2 m} \\
\cdots & \cdots & \cdots & \cdots \\
u_{n 1} & u_{n 2} & \cdots & u_{n m}
\end{array}\right]
$$

$D=\left(\left\{d_{1}, d_{2}, \cdots, d_{c}\right\}\right), 2 \leq c \leq n$ categories, and $c$ individuals cluster center vector is used to get the matrix $V$

$$
V=\left[\begin{array}{c}
V_{1} \\
V_{2} \\
\cdots \\
V_{C}
\end{array}\right]\left[\begin{array}{ccccc}
v_{11} & v_{12} & \cdots & v_{1 m} \\
v_{21} & v_{22} & \cdots & v_{2 m} & \\
\cdots & \cdots & \cdots & \cdots \\
v_{C 1} & v_{C 2} & \cdots & v_{C m}
\end{array}\right]
$$

\section{ONE ADVANCED FCM CLUSTER METHOD OF SPECIFICATION}

The FCM cluster based on extreme difference specification can use to nondimensionalize, and the cluster center number is $\mathrm{C}$, the fuzzy similar relationship is applied to get the equal matrix, in order to divide the cut set. Then, FCM cluster is applied to get the fault mode results. The Steps is as bellows:

Step1: Divide the sample fuzzy based on the equal relationship cluster of specification, and set $\mathrm{C}$ value, get the original subordinate degree matrix.

Step2: Extreme difference specification is applied in the nondimensionalization, and the comparison sequence is introduced in the specification formula

$$
x_{i j}=\frac{x_{i j}-x_{j \min }}{x_{j \max }-x_{j \min }},(i=1,2, \cdots, n ; j=1,2, \cdots, m)
$$

In which, $\quad x_{j \max }=\max \left\{x_{1 j}, x_{2 j}, \cdots, x_{n j}\right\}$, $x_{j \min }=\min \left\{x_{1 j}, x_{2 j}, \cdots, x_{n j}\right\}$.

Step3: Calculate the similar index $r_{i j}$, formulate the fuzzy relationship matrix $R=\left[r_{i j}\right]_{n \times n}$

Sample set is divided to 


$$
r_{i j}=\frac{\sum_{k=1}^{m}\left|u_{i k}-\overline{u_{i}}\right|\left|u_{j k}-\overline{u_{j}}\right|}{\sqrt{\sum_{k=1}^{m}\left(u_{i k}-\overline{u_{i}}\right)^{2}} \sqrt{\sum_{k=1}^{m}\left(u_{j k}-\overline{u_{j}}\right)^{2}}},(i, j=1,2, \cdots, n)
$$

Step4: Use the square method $R \rightarrow R^{2} \rightarrow R^{4} \rightarrow \cdots \rightarrow R^{2^{k}} \rightarrow \cdots$ to get the fuzzy equal relationship matrix $t(R)=R^{2^{k}}$;

Step5: Use the $\lambda$ cut set to divide, because the different subordinate degree $\lambda$ get the different $t(R)$, and the $C$ categories is got.

\section{ApPlication Analysis}

The algorithm is applied to some aviation equipment fault diagnosis, and "common transmitter and receiver" and "antijamming transmitter and receiver" are fault phenomenon, and the fault omen is the condition attribution " $C$ ", $C=$ \{frequency error $C_{1}$,UUT transmitter voltage $C_{2}$, UUT receiver voltage $C_{3}$, transmitter power $C_{4}$, host receiver sensitivity $C_{5}$, host receiver voice $C_{6}$, silence sensitivity $C_{7}$ \}, Table I gives 7 times test data and Table II gives the extreme difference specification results.

TABLE I. THE ORIGINAL TEST DATA

\begin{tabular}{|l|c|c|c|c|l|l|l|}
\hline No. & $\mathbf{C}_{\mathbf{1}}$ & $\mathbf{C}_{\mathbf{2}}$ & $\mathbf{C}_{\boldsymbol{3}}$ & $\mathbf{C}_{\mathbf{4}}$ & $\mathbf{C}_{\mathbf{5}}$ & $\mathbf{C}_{\mathbf{6}}$ & $\mathbf{C}_{\mathbf{7}}$ \\
\hline$(1)$ & 5.1 & 27.5 & 25 & 22.5 & 120 & 50 & 50 \\
\hline$(2)$ & 5.0 & 28.0 & 35 & 27.5 & 80 & 35 & 35 \\
\hline$(3)$ & 4.9 & 28.5 & 55 & 24.5 & 50 & 40 & 40 \\
\hline$(4)$ & 5.5 & 25.5 & 15 & 28.5 & 20 & 30 & 30 \\
\hline$(5)$ & 4.8 & 29.5 & 35 & 28.5 & 150 & 10 & 10 \\
\hline$(6)$ & 5.0 & 26.5 & 60 & 25.0 & 70 & 200 & 200 \\
\hline
\end{tabular}

TABLE II. THE EXTREME DIFFERENCE SPECIFICATION RESULTS

\begin{tabular}{|c|c|c|c|c|c|c|}
\hline No. & $\boldsymbol{C}_{1}$ & $\boldsymbol{C}_{2}$ & $\boldsymbol{C}_{3}$ & $\boldsymbol{C}_{4}$ & $\boldsymbol{C}_{5}$ & $\boldsymbol{C}_{6}$ \\
\hline$(1)$ & 0.42857 & 0.5 & 0.22222 & 0 & 0.76923 & 0.21053 \\
\hline$(2)$ & 0.28571 & 0.625 & 0.44444 & 0.83333 & 0.46154 & 0.13158 \\
\hline$(3)$ & 0.14286 & 0.75 & 0.88889 & 0.33333 & 0.23077 & 0.15789 \\
\hline$(4)$ & 1 & 0 & 0 & 1 & 0 & 0.10526 \\
\hline$(5$ ) & 0 & 1 & 0.44444 & 1 & 1 & 0 \\
\hline$(6)$ & 0.28571 & 0.25 & 1 & 0.41667 & 0.38462 & 1 \\
\hline
\end{tabular}

Through the similar relationship definition, the fuzzy relationship matrix $\mathrm{R}$ and the fuzzy equal matrix $t(R)$ are got after three times iterations.

$$
R=\left[\begin{array}{lllllll}
1 & 0.65902 & 0.63623 & 0.81932 & 0.79949 & 0.65498 \\
0.65902 & 1 & 0.57664 & 0.80438 & 0.85618 & 0.70799 \\
0.63623 & 0.57664 & 1 & 0.79362 & 0.78588 & 0.96881 \\
0.81932 & 0.80438 & 0.79362 & 1 & 0.91051 & 0.79298 \\
0.79949 & 0.85618 & 0.78588 & 0.91051 & 1 & 0.84688 \\
0.65498 & 0.70799 & 0.96881 & 0.79298 & 0.84688 & 1
\end{array}\right]
$$

$t(R)=\left[\begin{array}{lllllll}1 & 0.81932 & 0.81932 & 0.81932 & 0.81932 & 0.81932 \\ 0.81932 & 1 & 0.84688 & 0.85618 & 0.85618 & 0.84688 \\ 0.81932 & 0.84688 & 1 & 0.84688 & 0.84688 & 0.96881 \\ 0.81932 & 0.85618 & 0.84688 & 1 & 0.91051 & 0.84688 \\ 0.81932 & 0.85618 & 0.84688 & 0.91051 & 1 & 0.84688 \\ 0.81932 & 0.84688 & 0.96881 & 0.84688 & 0.84688 & 1\end{array}\right]$

Then, different subordinate degree $0 \leq \lambda_{1} \leq 0.81932$,

$0.81932<\lambda_{2} \leq 0.846880 .84688<\lambda_{3} \leq 0.85618$,

$0.85618<\lambda_{4} \leq 0.91051,0.91051<\lambda_{5} \leq 0.96881$,

$0.96881<\lambda_{6} \leq 1$ is used to divide $t(R)$ as the $\lambda$ cut set,

and the different 6 categories is as bellows:

$\begin{aligned} t(R)_{\lambda_{1}}= & {\left[\begin{array}{llllll}1 & 1 & 1 & 1 & 1 & 1 \\ 1 & 1 & 1 & 1 & 1 & 1 \\ 1 & 1 & 1 & 1 & 1 & 1 \\ 1 & 1 & 1 & 1 & 1 & 1 \\ 1 & 1 & 1 & 1 & 1 & 1 \\ 1 & 1 & 1 & 1 & 1 & 1\end{array}\right], t(R)_{\lambda_{2}}=\left[\begin{array}{llllll}1 & 1 & 1 & 1 & 1 & 1 \\ 0 & 1 & 1 & 1 & 1 & 1 \\ 0 & 1 & 1 & 1 & 1 & 1 \\ 0 & 1 & 1 & 1 & 1 & 1 \\ 0 & 1 & 1 & 1 & 1 & 1\end{array}\right], } \\ t(R)_{\lambda_{3}} & =\left[\begin{array}{llllll}1 & 0 & 0 & 0 & 0 & 0 \\ 0 & 1 & 0 & 1 & 1 & 0 \\ 0 & 0 & 1 & 0 & 0 & 1 \\ 0 & 1 & 0 & 1 & 1 & 0 \\ 0 & 1 & 0 & 1 & 1 & 0 \\ 0 & 0 & 1 & 0 & 0 & 1\end{array}\right], t(R)_{\lambda_{4}}=\left[\begin{array}{llllll}1 & 0 & 0 & 0 & 0 & 0 \\ 0 & 1 & 0 & 0 & 0 & 0 \\ 0 & 0 & 1 & 0 & 0 & 1 \\ 0 & 0 & 0 & 1 & 1 & 0 \\ 0 & 0 & 0 & 1 & 1 & 0 \\ 0 & 0 & 1 & 0 & 0 & 1\end{array}\right], \\ t(R)_{\lambda_{5}} & =\left[\begin{array}{llllll}1 & 0 & 0 & 0 & 0 & 0 \\ 0 & 1 & 0 & 0 & 0 & 0 \\ 0 & 0 & 1 & 0 & 0 & 1 \\ 0 & 0 & 0 & 1 & 0 & 0 \\ 0 & 0 & 0 & 0 & 1 & 0 \\ 0 & 0 & 1 & 0 & 0 & 1\end{array}\right], t(R)_{\lambda_{6}}=\left[\begin{array}{llllll}1 & 0 & 0 & 0 & 0 & 0 \\ 0 & 1 & 0 & 0 & 0 & 0 \\ 0 & 0 & 1 & 0 & 0 & 0 \\ 0 & 0 & 0 & 1 & 0 & 0 \\ 0 & 0 & 0 & 0 & 1 & 0 \\ 0 & 0 & 0 & 0 & 0 & 1\end{array}\right],\end{aligned}$

The related partitions are $\left\{\mathrm{C}_{1}, \mathrm{C}_{2}, \mathrm{C}_{3}, \mathrm{C}_{4}, \mathrm{C}_{5}, \mathrm{C}_{6}\right\}$

$$
\begin{aligned}
& \text { and }\left\{\mathrm{C}_{1}\right\},\left\{\mathrm{C}_{2}, \mathrm{C}_{3}, \mathrm{C}_{4}, \mathrm{C}_{5}, \mathrm{C}_{6}\right\} \\
& \text { and }\left\{\mathrm{C}_{1}\right\},\left\{\mathrm{C}_{2}, \mathrm{C}_{4}, \mathrm{C}_{5}\right\},\left\{\mathrm{C}_{3}, \mathrm{C}_{6}\right\} \\
& \text { and }\left\{\mathrm{C}_{1}\right\},\left\{\mathrm{C}_{2}\right\},\left\{\mathrm{C}_{4}, \mathrm{C}_{5}\right\},\left\{\mathrm{C}_{3}, \mathrm{C}_{6}\right\} \\
& \text { and }\left\{\mathrm{C}_{1}\right\},\left\{\mathrm{C}_{2}\right\},\left\{\mathrm{C}_{4}\right\},\left\{\mathrm{C}_{5}\right\},\left\{\mathrm{C}_{3}, \mathrm{C}_{6}\right\} \\
& \text { and }\left\{\mathrm{C}_{1}\right\},\left\{\mathrm{C}_{2}\right\},\left\{\mathrm{C}_{4}\right\},\left\{\mathrm{C}_{5}\right\},\left\{\mathrm{C}_{3}\right\},\left\{\mathrm{C}_{6}\right\} \text {. }
\end{aligned}
$$

\section{CONCLUSION}

The paper introduces the extreme difference specification method to FCM cluster, and the improvement algorithm is proposed and applied to some equipment fault diagnosis for getting the cluster results, which helps the next fault determination. It provides a new way to the fuzzy equipment fault diagnosis. 


\section{REFERENCES}

[1] Wang Liang, Wand Shitong. New Noise-Resistant Fuzzy Clustering Approach and Ifs Application in the Fault Diagnosis of Ship[J] Microcomputer Information, 2011,27(9):82-85.(in Chinese)

[2] Yang Yi-fang, Ding Zhengsheng. Application of mixed fuzzy clustering analysis for diagnosis of vibration faults [J]. Computer Engineering and Design, 2008,29(14):3785-3789.(in Chinese)

[3] Sergios Theodoridis, Konstantinos Koutroumbas. Pattern recognition[ M].Beijing: China Machine Press, Sep. 2003.

[4] Wang Shitong, J. F. Baldwin, T. P. Martin Hierarchical Mass Assignment Fuzzy System of Two Types as Universal Approximation [J]. Journal of Software, 2002, 13(10):1943-1951.

[5] Zhang Xingfang. Simplification of addition and subtraction operations of fuzzy numbers [J].The Journal of Fuzzy Math, 2002, 32(4):959-968.

[6] Li Peng, Chen Zhongyi. Fault Diagnosis Method Based on Fuzzy Clustering[J]. Modern Electronics Technique,2010,23(334):119-121 